\title{
The Interface Between Participatory Local Social Development (PLSD) and Andragogy in Improved Opportunities and Obstacles to Development (O \&OD) System in Tanzania
}

\author{
Hagai Joseph Mwakisisya \\ Local Government Training Institute- P. O Box 1125, Hombolo, Dodoma,Tanzania
}

\begin{abstract}
*This paper was first presented at the Special Joint Conference of the Academy of International Business Africa and United States Northeast Chapters, held at United States International University-Africa, Nairobi, Kenya on January 6-9, 2020.

Abstract

The Improved Opportunity and Obstacles to Development (O and OD) is a bottom-up approach that uses participatory Local Social Development (PLSD) framework to empower the communities to develop themselves. PLSD holds that the three fundamental elements for development and sustainability are; norms, organization and resources. It further postulates that development has to be community-based whereby the people are able to organize themselves to identify the community felt-problem and effectively utilize the available resources to bring about a solution, a felt-need. On the other hand, andragogy is the training model for adults in the field of education which characterizes them as problem-centred, self-directed and learners with a vast experience. Despite this glaring difference, the improved $\mathrm{O}$ and $\mathrm{OD}$ which is a community development approach has simultaneously and systematically employed both PLSD and andragogy in its rolling out. This study, therefore, sought to find out the compatibility between PLSD, a community development approach, and andragogy in the implementation of $\mathrm{O}$ and OD. The study was conducted in Morogoro Municipal and Chalinze District Council. Interviews administered to 11 key informants, focus group discussion involving 72 participants, observation and documentary reviews were used in data collection. The collected data were analyzed and the themes were generated. The study found that there is great compatibility between PLSD and andragogy because: both are beneficiary-based, both are problemmotivated, in both approaches experience is an important factor for achievement. This study maintains that training methodologies need to evoke self-reliance, independence and creativity which are inalienable factors for bottomup approach in community development.
\end{abstract}

Keywords: Participatory Local Social Development, Andragogy, O and OD

DOI: $10.7176 / \mathrm{JEP} / 11-14-10$

Publication date:May $31^{\text {st }} 2020$

\section{Introduction}

Improved Opportunities and Obstacles to Development (Improved O and OD) is a participatory community planning process which aims to empower the people through a bottom-up approach (Mlupilo 2005) The O\&OD planning methodology has been developed to serve as an engine to empower the grassroots and enhance service delivery for poverty eradication (Cooksey \& Kikula 2005). The Improved O and OD came as a response to an inefficiency of the former conventional version caused by its largely top-down approach as indicated in the study by Prime Minister's Office-Regional Administration and Local Government (United Republic of Tanzania-URT 2008). The new version advocates for participatory approach to create a sense of ownership, self-reliance and reduces dependency syndrome among the grassroots (Mwanga 2011). Improved O\&OD is a methodology to build and sustain collaborative relationships between Local Government Authorities and communities for better service delivery by empowering communities and promoting Community Initiatives (URT 2019).

The improved $\mathrm{O}$ and OD is rolled out, primarily, through training of Local Government Officials (Mwakisisya 2020). The training methodologies owe a lot from andragogy, a training philosophy by American educationist Knowles (Mwakisisya 2020). The trained officials are, in turn, expected to use the acquired content to mobilize their people for different development projects, thus implementing Participatory Local Social Development (PLSD) which is a community development participatory approach.

\subsection{Participatory Local Social Development (PLSD) Framework}

PLSD is a bottom-up approach in community development which was developed by Japanese participatory community development expert Yutaka Ohama. In his book Participatory Local Social Development - An Emerging Discipline (2007) Professor Ohama observes that the main goal of PLSD is to facilitate the process of building capability and strengthening institutional mechanism of a society as a whole toward self-reliant and sustainable development. It also aims to internalize the use of Participatory Approach (AP) in terms of capability building and institutional development in project activities (Sharma and Ohama 2007). It is a participatory community based model employed by improved $\mathrm{O}$ and $\mathrm{OD}$ system to empower the people in developing 


\section{themselves.}

PLSD has two outstanding characteristics, which are sometimes overlooked in the assistance by external donors, namely "sustainability" and "viewpoint from overall long-term development process". Talking of sustainability, it is very difficult to maintain sustainability on development projects, especially in less developed countries (Sharma and Ohama 2007). Many projects, especially, those with external assistance fail upon expiration of the assistance because the external assistance itself tends to play the main role in implementing the activities with the local people's less involvement (Sharma and Ohama 2007, Ohama 2002). To enhance sustainability in any development project, PLSD stress is on the importance of capability building of "Local Societal System" by fully taking into consideration people's tradition, experience, resources, to name but a few (Ohama 2001, Sharma and Ohama 2007). Local Societal System is composed of local stakeholders such as local community, local market, local government and NGOs (Sharma and Ohama 2007). When the Local Societal System is strengthened through capability building, it becomes possible for the community to take appropriate actions for further development.

PLSD pays a special attention to the "viewpoint from overall long-term development process". According to PLSD, one project is but a one step in the overall long-term development process. It therefore focuses, not only on the achievement of the project, but also on the capacity building of overall Local Societal System for the sustainable long-term development (Sharma and Ohama 2007, Yogo 2001).

According to PLSD framework, there are three fundamental elements for development and sustainability, namely; norms, organization and resources (Sharma and Ohama 2007). The Norms are rules and regulations that govern the community. Development and sustainability of projects and the entire community depend on strong rules and regulations. There are two types of norms, namely; Cognizant norms, these are cultural based rules, for example, helping a member who has lost their loved ones. Cognizant norms are represented by collaboration, participation, cooperation by community members (Sharma and Ohama 2007). In community development facilitation, a lot of attention and consideration should be extended to cognizant norms as they can also be catalysts of development. Operational norms, these are functional rules, for examples setting an entry fee to join a certain social group, or setting constitutions for a social group. The other element is organization whereby people organizing themselves in social groups or administrative units in order to strengthen their self-help efforts to solve their problems. This organization becomes more effective when guided by the norms. Furthermore, resources are also an important aspect in PLSD framework. They include human resource, physical resource such as land, forest, water bodies, and financial resource ( Sharma and Ohama 2007, Mwanga 2011, URT 2019). The three elements of development by Sharma and Ohama (2007) correspond with Tanzania first President, Mwalimu Julius K. Nyerere's four prerequisites for development which are (i) People; (ii) Land; (iii) Good Policies; and (iv) Good leadership (Nyerere 1977: 29). The correspondence goes thus: (i) People (human resource), (ii) Land (natural resources), (iii) Good policies (norms) (iv) Good leadership (organization)

Sharma and Ohama (2007) add that effective utilization of resources needs strong organization with strong norms, capability building and institutional linkage through networking. Capability building is enabling the community through facilitation and awareness creation to identify the available resources and effectively using them. It is also about empowering the community to organize themselves, set rules and regulation (norms) to guide them to use the available resources for development. Institutional linkage is also important because no community can prosper in isolation, linking it with outsiders like government, non-government organizations and individuals is important (Mwanga 2011, URT 2019).

Thus, PLSD advocates for the community to be able to self-organize and use the above mentioned factors for sustainable development. With a guidance from the facilitator, the community member need to identify the feltproblem, then organize themselves to use the available resources to get a felt-need (solution to the felt-problem). Finding a solution to the problem provide the local members with the experience to start new projects or community initiatives that will solve other community challenges (Sharma and Ohama 2007)

The diagram below summarizes the inter-relationship between the factors for development (Sharma and Ohama 2007)

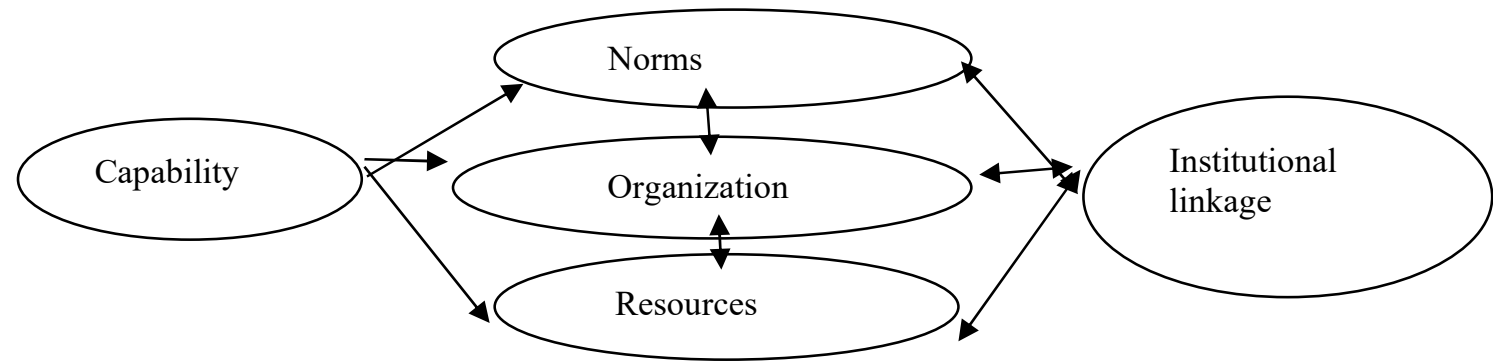

(Sharma and Ohama 2007:132)

Norms, organization and resources are key elements for development. For the community to develop itself 
using the three elements, capability building is important. Capability building can be on enabling the community to set effective operational norms to run its projects sustainably or capitalize on good existing traditional norms (cognizant norms) to develop itself. In addition to that, capability building can target to enable the community to effectively use the available resources. Thus, capability building aims at enabling a community to plan and implement its own self-help efforts. Since no community can develop in isolation, institutional linkage is indispensable. A community develops relationship with NGOs, Government Organizations, institutions and sometimes individuals. Institutional linkage or relationship can be on the aspect of norms, for instance, when a community or a social group seeks or extends help to other communities or institutions in setting up a constitution. Other aspects of institutional linkage can be resources available in a community or even the organization itself. The PLSD framework acknowledges community participation and community based management to be important in community development (Mwanga 2011). Studies reviewed here expound the theoretical part of PLSD, they lack its empirical outlook. There is hardly any empirical study on PLSD. Cooksey \& Kikula (2005) and Mlupilo (2005), mentioned earlier, deal with the old version of O and OD which did not employ PLSD. These studies characterize the old version as lacking active community participation as the community took part in development planning by listing what should be done for them or setting priorities for the government to implement. In the view of this, the government of Tanzania in collaboration with JICA initiated the improved O and OD with PLSD framework.

\subsection{Andragogy}

Being a model for adult learning, Andragogy, is a learner-centred teaching philosophy assuming students are independent and sovereign learners who take the initiative in, control of, and responsibility for achieving their learning goals, and the teacher plays the role of a facilitator, emphasizing the problems rather than the content (Knowles 1980, Merriam and Caffarella 1999, Ekoto and Gaikwad 2015, Reischmann 2017). According to Blondy (2007) and Knowles et al (2014) andragogy contrasts sharply with pedagogy, which maintains that learners are dependent personalities who bring little or no experience to the educational activity and learners attend to such activities because they have been told to do so. The proponents of andragogy delineate qualities that make adults a group of learners with special needs as: learners who has seen the Need to Know. Adults want to know why they need to learn something before undertaking learning. Adults become ready to learn things they need to know and do in order to cope effectively with real-life situations (Knowles 1984). In addition to that is the learners' selfconcept. Adults believe they are responsible for their lives, they need to be seen and treated as capable, independent and self-directed. Thus, according to Brookfield (1986) facilitators should create environments where adults develop their latent self-directed learning skills. The other important adult learners' trait is their vast knowledge they gather from experiences which is useful in the process of learning (Knowles 1980, Tahir et al 2014, Alajlan 2015, Reischmann 2015).

In connection to that adult learners are characterized by the readiness to learn. Unlike children, adults become ready and motivated to learn things they need to know and do in order to cope effectively with real-life situations (Knowles 1980, Ferreira and MacLean 2017) According to Knowles (1984) adults learn primarily out of necessity and that triggers their readiness. Adult learners are problem oriented. Adults are life-centered (task-centered, problem-centered) in their orientation to learning (Knowles et al 1984, Greene and Larsen 2018). They want to learn what will help them perform tasks or deal with problems they confront in everyday situations and those presented in the context of application to real-life (Merriam \& Caffarella, 1993). Proponents of andragogy (Knowles 1980,1984, Brookfield 1986, Merriam and Caffarella 1999, Blondy 2007, Alajlan 2015, Loeng 2017) do not directly link this model to community development. Moreover, these studies merely dwell more theoretically on the qualities and needs of the adult learners, they hardly consider the actual and on-ground application of the content learned during training.

Mwakisisya (2020) study on meeting adult learners' special needs in O and OD trainings acknowledges efficiency of andragogy. The study unearths the training methodologies that suits and appreciate qualities of adult learners as outlined in the andragogy. Mwakisisya ( ibid.) observes that methodologies like case studies, role plays, field study visits, discussions and presentations are so involving and make the adult learners active and enjoy the learning. Although the study acknowledges that such training methodologies spark creativity and self reliance as well as aiding memory retention of the content learned, the study does not feature PLSD.

\section{Statement of Problem}

Being a community development framework, it is understandable why PLSD by Ohama (2001), Ohama (2001) and Sharma and Ohama (2007) does not feature andragogy or any other forms of training. Andragogy is a philosophy of adult learning, and thus falls in the field of education (Knowles 1980, 1984, Brookfield 1986, Merriam \& Caffarella 1993, Merriam and Caffarella 1999, Blondy 2007, Knowles et al 2014, Alajlan 2015, Ferreira and MacLean 2017, Loeng 2017, Greene and Larsen 2018). Despite this glaring difference, the improved $\mathrm{O}$ and $\mathrm{OD}$ which is a community development approach has simultaneously and systematically employed both 
PLSD and andragogy in its rolling out. This synergy creation stirs a very special interest. Moreover, there is dearth of empirical studies on O and OD and indeed on PLSD framework. This study therefore aims to investigate the interface between PLSD and andragogy, it specifically seeks to find out the compatibility between PLSD framework and andragogy in improved $\mathrm{O}$ and OD system in Tanzania.

\section{Research Methodology}

This study was conducted during the improved O and OD trainings and field visits that were done in Morogoro Municipal and Chalinze District Council. Morogoro Municipal and Chalinze District Council are among the areas where improved $\mathrm{O}$ and OD is being rolled out (PMO-RALG 2008). The study adopted a qualitative descriptive design as it sought to get views on the rolling out of improved O and OD. Qualitative research tools included, indepth interviews with key informants Focus Group Discussion and documentary reviews.

In-depth interviews were conducted with the key informants who were: The Improved O and OD National Adviser, District Community Development officers, 2 Ward Executive Officers from Maseyu and Chalinze wards respectively and 2 Village Executive officers from Maseyu and Chamakweza villages. The in-depth interview was also administered to 2 Senior Facilitators from President Office-Regional Administration and Local Government (PO-RALG) as well as 3 Master trainers from Local Government Training Institute. An in-depth interview is a qualitative research technique that involves conducting intensive individual interviews with a small number of respondents to explore their perspectives on a particular idea, program, or situation (Boyce and Neale 2006). The interviews were tape-recorded at the interviewees' consent. Through interviews the researcher was able to understand participants' opinions and views regarding training, its methodologies, contents and their application.

Focus Group Discussions was another methodology in data collection. The FGD stimulated participants to reveal essential information about their opinions, beliefs, perceptions and attitudes towards the improved $\mathrm{O}$ and OD trainings. The FGDs were done in two parts: the first part was conducted during the training days immediately after the sessions. There were 5 groups and each group has a total of 6 members. A total of 9 Focus Group Discussions were conducted. At the participants' consent the discussion was audio-taped. With focus group discussion it was possible to exhaust all the methodologies used for training, members reminded each other about every method that is applied during the training. This encouraged each member of a group to speak their opinions about the methodologies, content and their application freely.

The second part of the FGD was done in the wards where the rolling out of improved O and OD is implemented by the trained local government officials and their communities. These wards were Chamakweza in Chalinze and Maseyu in Morogoro Municipal. The participants were the community members. In each wards 3 FGD were conducted, each group being composed of 7 participants, giving a total of 42 respondents. During the FGD by the community members, the researcher was interested in learning the efficiency of improved O and OD in sparking self-reliance.

Observation as the name suggests is a way of collecting data through observing. It is a social research technique that involves the direct observation of phenomena in their natural setting while taking recording. In each training session the researcher was so keen on how the participants were taking part in every aspect of transactions. Different community initiatives or projects were observed as well. It enabled the researcher to get information that subjects could not tell. Thus, through observation, the researcher was able to learn participants' attitude towards the trainings.

Other data came from documentary review. Documents Reviewed included the evaluation forms, the evaluation is done by the trainees to express their feelings at the end of each training retreat. The researcher also had a thorough look on the handouts used for training, from the handouts the researcher found out the content and activities for learners. The study by Mwakisisya (2020) on training methodologies used in the rolling out of $\mathrm{O}$ and OD was also used as a source of data. The use of a variety of data collection methods in this study - interviews, FGDs and documentary review - helped the study to benefit from the strengths of each method and to offset their weaknesses in collecting valid and reliable data.

Since this is a qualitative descriptive study, the thematic analysis was used for data analysis (Creswell 2009). The analysis was done through the following steps: First, audio data recorded from the in-depth interviews and FGDs were transcribed to produce written text. Then, the textual data including documentary review information were repeatedly read through to establish a general understanding and to reflect on their overall meaning. Second, the author organised the data to produce themes.

\section{Results}

This part presents the interface between PLSD and andragogy. The themes are made of the factors that represent interface or compatibility between these two models.

\section{i. $\quad$ Problem-centeredness}

Both PLSD and andragogy were found to be problem-centred approaches. In both approaches the problem was seen to be a pushing factor for action. 
PLSD: the study found that in the implementation of PLSD, identification of the felt-problem is crucial before the community embark into looking for solution., it is in fact a can't-wait matter. A project will be successful and sustainable only if it solves the felt-problem. Felt-problem is a main force and motive behind any development project. People will not embark into a project with zeal if it is not geared towards solving a real problem that they face. One of the improved $\mathrm{O}$ and OD facilitators observed;

Felt-problems are hardships which the people have been suffering from and thus, sincerely, want to overcome. It is a pressing and tormenting difficulty that needs to be addressed. It is important for both the community and the facilitator to clearly understand the felt-problem. A good facilitator should be able to enable the community to identify the felt-problem. A felt-problem can be truancy among the pupils, disease. or even death.

The urge to solve a problem is a motive behind community initiatives. A progressive community is the one that is able to identify a felt-problem. Dealing with the genuine problem attracts the attention and efforts of all members in the community. It is also a duty of a facilitator to enable the community in identifying the felt-problem.

Andragogy: during the study it was seen that the local government officials who attended the training felt handicapped and needed the knowledge to improve their work performance, which proves that adult learners are problem-centered. This means that an adult embark in learning business to acquire content and skills that will help him to grapple with difficulties and problems. Thus, lack of knowledge and skills is a motive behind learning. The lack of knowledge is reflected in inability of a person to perform his duties. But also an adult may find it a problem when not entrusted to serve in a certain post because of not having the required knowledge and skills. But also the problem could be that which touches the entire community like mismanagement of the public fund, the adult learner will give in to learning to solve it. Consider some of the comments from the O and OD trainees:

I'm interested to see every person in my ward to take part in development projects, but I lack skills to persuade them. People in my ward lack feeling of ownership for development projects, and so their participation is very low. In our village we had leaders who didn't like to share financial report, income and expenditure report, as a result there were financial appropriation and mismanagement. we went on study visit to Tulo village in Morogoro, we found the village leaders shares income and expenditure report through noticeboard. That was a great lesson to us!

Therefore, an adult needs a content and skills from the training to be able to overcome the problems is facing.

It can safely be concluded that in both approaches, a problem is a reason for an adult to embark in learning as it is for the community to initiate a project.

ii. $\quad$ Felt-need/solution identification

The study further noticed that both PLSD and andragogy are felt-need or solution driven. Felt-need is a solution to the existing problem.

PLSD: It was noted that a search for a solution to a problem motivated the community into action. felt-need is what the community crave to have to solve a tormenting problem. It is what the community can not wait to get or a can't-do-without. The community has to be able to identify their real need to overcome the real problem. A people embark into a certain community initiative because they want to achieve a need to fix the problem they face. Identifying a need is the most important step to ensure sustainable participatory development process of the community. With the felt-need in sight the community does not wait for assistance or wait for someone to do for them, they tirelessly work to achieve it to end the tormenting problem. A felt-need could be a meal provision at school (to end truancy among pupils) or a health-facility (to end a disease or rampant death). The following comment from a village chairperson will cement our understanding on a felt-need.

'Our pregnant wives, sisters had to walk a very long distance to the health facility in town, some delivered on the way and even death occurred. We have been waiting for the government to build a dispensary in our neighborhood to no avail, so we decided to do it ourselves. Everybody participated fully towards that goal. And here we are, the village dispensary is here, our wives are no longer walking for hours to a health facility, we no longer hear bad news delivering or even dying on the way'.

The felt-need is a driving force for their participatory development. After witnessing the death of their loved wives and sisters, the villagers decided to work towards attaining a felt-need, a dispensary, to solve the problem. The community participation is very high when the felt-need identified addresses their problem, it is, conversely, very low when the felt-need is not real. Let us consider what the other village chairperson relates:

'In our village we have a number of water wells, and therefore there is a passive response from the people towards water tape project'.

Since there are a number of wells in this village, water tape is not their felt-need and so their participation is passive. Andragogy: adult go into learning when they fell into need. The need for an adult is the knowledge and skills that will enable to face the challenges. The adult learner embraces the content that is applicable to the current situation. On the application of the content they received during the training, the $\mathrm{O}$ and OD trainees shared the following observation;

This training enables us with the skills and knowledge to persuade people to take part in community development projects, something we were in dire need of. 
Adult learners become active in learning when they know why they learn, they become passive when the content does not cater for the current situation. Thus, when the need is not properly identified and thus not met both in community development (PLSD) and in learning (andragogy), the key actors, community members and learners, respectively, become bored and dull.

\section{iii. Using available resources/Experience}

In both PLSD and andragogy, effective utilization of available resources in their different forms was found to be vital.

PLSD: It is important for a community to identify and effectively use the available resources in their move to bring about development. types of resources are human resources, financial resources, physical resources like land, forest, water bodies, minerals. According to PLSD community development starts with the available resources, the community must understand how to effectively use them. Many of the problems that the communities are facing can mostly be solved by fully utilization of all the available resources. To put that into perspective, notice the mobilization and effective utilization of resources as one of village members shares the following experience: Deaths of patients, especially the expectant mothers on their way to a very far health facility were an order of the day. However, at some point in time the villagers decided to build a dispensary of their own. In the process, the resources used, were mobilized from within the village. Bricks were made by the villagers, especially men while women fetched water, men were also responsible to make kiln for baking bricks. The construction was done by village masons/local fundis. Moreover, the villagers had to sell chickens and bricks to raise money and subsequently make a contribution for purchasing other building materials like cement, iron sheets, timbers. The village, at last, managed to build its own dispensary at an estimated cost of 52,000USD, something they considered out of their reach.

This experience is an immense lesson that with effective utilization of the available resources a community can overcome problems even those seem insurmountable in the first place. The resources in all their different forms, when mobilized for community development, are more effective than any other assistance a community may receive from the outsiders. Experience-based learning is an important ingredient of PLSD framework. The community learn and accumulate the experience from the community initiative/project they engage in. The accumulated experience is used to start another project.

Andragogy: Implicitly, available resources that are very important for the adult training is the knowledge and experience they have gathered over the course of time. Adult learners have a vast experience that has to be fully exploited during the training. The adults appreciate the lesson that makes use of their experience. During the $\mathrm{O}$ and OD training the local government officers who are the trainees share a lot of experiences which have proved to be very useful during the training. Since the training is about community participation in development, the trainees bring the success stories as well as challenges they face during planning and implementation of development projects.

'During this training we shared a lot of experience from different wards and villages, and we also discussed how the lesson content can be used in overcoming the obstacles to development. These experiences have made the learning meaningful.'

Thus, both models insist on the effective use of available ingredients; resources and experience as key elements of success for community development (PLSD) and learning (andragogy) respectively. In a word, both models believe in 'start with what you have'.

\section{iv. Beneficiary based}

During the study it was noted that both PLSD and andragogy are beneficiary based. A beneficiary either of community development or of training took a leading role in the processes.

PLSD: Since the local community is the beneficiary of development process, it follows that it has to take a centre stage, outsiders are mere facilitators. The community has to identify the real problem that it is facing. The problem is normally revealed by looking at the endevours the community is making in order to solve it. Identification of an influential person to lead the process of development is done by the community members themselves through indepth discussions. According to PLSD framework the local communities has, first, to recognize and understand the problem that they face. Secondly, the community members have to critically their situation in the context of overall societal structure. Then, they should organize themselves for problem solving. This is done by jointly participating in the planning, implementation, and evaluation of the project. All of these are done after facilitation has been done to empower the community. The facilitator has to realize from the beginning he does not have a permanent tenure with the people and as soon as people accumulate the experiences in self-reliant project management he has to withdraw himself gradually. Experience from Chamakweza village, in Coastal region, predominantly Maasai and thus a pastoral community is very telling on how this is done. The traditional leader 'leguanani' had this to tell;

We as a pastoralist community, the importance of water can not be overemphasized. The water we had before was not enough and as a result we lost many herds of cattle. But after the arrival of JICA people, our eyes were opened, they helped us to understand that by using our own resources we can join our hands and dig a number of charcoal 
dams enough for our animals. And we did that. Even after departure of JICA people our self-help spirit did not die, we have been able to build our own primary school. We have started building a secondary school, three classrooms have been erected so far.

This experience is an indication that communities can develop themselves. The awareness creation they received from JICA facilitators has enable them to plan and implement their projects on their own. This society is already self-reliant.

Andragogy: this is a learner-centred teaching philosophy which posits that students are independent and sovereign learners who takes the initiative and responsibility to achieve their learning goals, and the teacher plays the role of a facilitator, emphasizing the problems rather than the content. The learners are involved in learning planning (what do they expect, how are they going to benefit from training). More over the training methodologies should be learner-centred and involving, so as to spark active learning and creativity. This kind of training should enable a learner to do on their own, even in the absence of a trainer. Mwakisisya (2020) maintains that for a learnercentred training to take place the improved $\mathrm{O}$ and OD employs the following methodologies:

Role-plays: Role-plays are composed and performed by trainees themselves. The trainees organize themselves in groups This is a very involving method of presenting content and makes the learning process fascinating.

Field study visits: These are visits to different places where $\mathrm{O}$ and OD is being implemented and case studies which are also widely used to provide trainees with the first hand experiences. Before going to the field, the trainees set the objectives and identify the areas where they think need to be learnt while there. This is, indeed, self-reliance. A case study: This presents a situation about a failed project or success story of a certain community project, the trainees read them, explain, in their groups, the reasons behind either failure or success of the project.

Discussion: This is a dominant strategy in O and OD trainings. Discussion works with almost every other training methodology. There are discussions on case studies, role-plays and filed study visits.

Presentations: They are an important factor in O and OD training. Presentations come after group discussions. Each group makes a presentation on case studies, role-play contents and field study visits.

Mwakisisya (2020) maintains that role-playing, field visits, case studies, discussion and presentations are very involving and thus learner-centered. It is, here, clearly noted how both PLSD and andragogy are beneficiarycentred. We see how both approaches create a space for the trainer and the community to take a centre stage in the processes of learning and community development respectively. The beneficiaries take a full responsibility in both models.

v. Reflection and action (Praxis)

During the study reflection and action featured in both PLSD and andragogy.

PLSD: The community take action and do the reflection. Reflection on the action leads to reproduction of community initiative or project. An experience related by one of the villagers helps to clarify the action and reflection;

'After constructing a dispensary, we didn't end there, we are now embarking on a journey to reduce the number of mud-walled and thatched houses. We have organized ourselves in groups and started a Baked-bricks Rotating Credit and Saving Association to enable every household to have a brick house roofed with iron sheets.'

Thus, we see a reflection on action to have a dispensary have reproduced another project.

Andragogy: a reflection on action was also seen in trainings the learners. After the end of each training retreat, the trainees were given a room to give their comments on how the content and methodologies of training can be improved. Through a reflection, the trainees showed the ability to review the training session and be able to give constructive ideas on the training improvement through 'Evaluation Forms'. For instance, the idea of translating the learning materials from English to Kiswahili was originally conceived by trainees. This is a result of reflection and action at the end of each session and training retreat.

In both andragogy and PLSD the beneficiaries were seen to be responsible for their life and take initiative to solve problems they faced.

\section{Discussion of the findings}

It is important for the training methodologies for the adults to be involving so as to spark self-reliance, independence and creativity which are inalienable factors for bottom-up approach in community development. Training programmes should be a reflection of the desired outcomes in the field. Andragogy adopted by improved $\mathrm{O}$ and OD perfectly complements the PLSD framework as it inculcates the spirit of independence and participation among the community members through trained local government authorities. The graduates of the training are capable of engaging the communities in taking the leading role in solving their own problems instead of waiting for the government or non-government organization to do for them. As we have seen in the studied areas the dependence syndrome has decreased significantly.

To a community which has embraced self-reliance and creativity, problems are blessing in disguise as they are a motivating factor to an action. Facilitators should create environments where community members develop their latent self-directed potentials and skills. The improved $\mathrm{O}$ and OD aims to fight the propensity of communities, 
especially, in developing countries to be dependent on the government, non-government organizations (NGOs) or individuals. It instead advocates for development process which is community based. The community, which is a beneficiary of a development process should take a leading role, other stakeholders like NGOs may join as mere facilitators of the process.

This study has clearly showed how the improved O and OD system fights dependence syndrome right from the way it prepares the local government officials during the training to the implementation of different development projects through PLSD framework. During the training the learners are not mere passive recipients, they are fully engaged in the learning process. The training is a forum for them to fight dependence and develop a spirit of creativity and self-reliance. Creativity and self-reliance are further transferable to the ground, where the local government officials inculcate these two important qualities onto members of the community. By delineating the similarities between andragogy and PLSD, this study has revealed the on-ground and actual application of the methodologies and content learnt during training in the implementation of community development projects.

The following table summarizes the areas in which andragogy and PLSD are compatible in improved O and OD in Tanzania.

\begin{tabular}{|c|c|}
\hline \multicolumn{2}{|c|}{ In both andragogy and PLSD a felt-problem (a can't-wait matter) is a motive behind the action. } \\
\hline $\begin{array}{l}\text { andragogy: inability to perform due to lack of skills } \\
\text { and knowledge is a motive behind joining training }\end{array}$ & $\begin{array}{l}P L S D \text { : felt-problems like health problems, poverty } \\
\text { are motivating factors for action }\end{array}$ \\
\hline \multicolumn{2}{|c|}{$\begin{array}{l}\text { In both andragogy and PLSD a felt-need/solution (a can't-do-without) is a driving force for } \\
\text { action }\end{array}$} \\
\hline $\begin{array}{l}\text { Andragogy: a felt need is knowledge and skills to } \\
\text { perform duties like mobilizing people for community } \\
\text { initiatives. }\end{array}$ & $\begin{array}{l}\text { PLSD: felt-need are dispensaries, clean and safe } \\
\text { water etc. }\end{array}$ \\
\hline \multicolumn{2}{|c|}{ Both approaches advocate for effective utilization of available resources and experience } \\
\hline $\begin{array}{l}\text { Andragogy: available resources are knowledge and } \\
\text { vast experience the adult learners have acquired in } \\
\text { their working life. They are very useful in the learning } \\
\text { process. }\end{array}$ & $\begin{array}{l}\text { PLSD: Resources for community development are } \\
\text { human resources, financial resources, physical } \\
\text { resources like land, forest, water bodies, minerals } \\
\text { etc. }\end{array}$ \\
\hline \multicolumn{2}{|c|}{ Both andragogy and PLSD are beneficiary based } \\
\hline $\begin{array}{l}\text { Andragogy: the trainings are learner centered. A } \\
\text { learner is a self-reliant needing only } \\
\text { guidance/facilitation. }\end{array}$ & $\begin{array}{l}\text { PLSD: development process is community based. } \\
\text { A community is self-reliant. It is provided with } \\
\text { guidance/facilitation }\end{array}$ \\
\hline \multicolumn{2}{|c|}{ Reflection and action (Praxis) } \\
\hline $\begin{array}{l}\text { Andragogy: reflection after the session is done for the } \\
\text { improvement in the next session }\end{array}$ & $\begin{array}{l}\text { PLSD: The community reflect on a community } \\
\text { initiative/project before going for the next stage or } \\
\text { starting a new project. }\end{array}$ \\
\hline
\end{tabular}

Table 1. The compatibility between andragogy and PLSD

\section{Conclusion}

This study details the dovetailing and compatibility between andragogy and PLSD. The findings indicate the features that straddle andragogy and PLSD in implementing improved O and OD system in Tanzania. The study found that adult learners embark into learning to be able to handle the problem they face in their working place. At the community level it is also the problem that motivate the community to take action towards solving problem. Moreover, in both andragogy and PLSD a felt-need or solution to a problem is a motive behind the action. Furthermore, these two approaches advocate using of available resources and experience. According to PLSD the community can develop by effectively utilizing the available resources, namely human, physical and financial resources while implicitly in andragogy adult learners' vast experience and knowledge are the available resources that have to be fully utilized in the training. Both in community development and in training of the adult, the beneficiary, that is the community and the learner respectively, should be at the center of the processes by being independent and self-reliant. Success in both approaches lies on the reflection and action (Praxis). In training and community development projects, there is a room to reflect on what has been done followed by actions, this ensures improvement.

A combination of andragogy and PLSD in improved O and OD create a convenient environment in which trained local government officials are given a chance to practice what they learned. The training methodologies spark creativity and self-reliance, the traits graduates are expected to demonstrate while carrying out community 
development projects. There is a need for the training institutes and other stakeholders to make a comprehensive mechanism to assess their graduates on the implementation of the acquired training contents. This will help in designing training methodologies that reflect what is desired in the field.

\section{References}

Alajlan A.S (2015) Applying Andragogy Theory in Photoshop Training Programs. Journal of Education and Practice ISSN 2222-1735(Paper) ISSN 2222-288X (Online) Vol.6, No.25, 2015

Blondy L. C (2007) Evaluation and Application of Andragogic Assumptions to the Adult Online Learning Environment. Journal of Interactive Online Learning. Volume 6, Number 2, Summer 2007 ISSN: 1541-4914

Boyce C and Neale P (2006) Conducting In-depth Interviews: A Guide for Designing and Conducting In-Depth Interviews for Evaluation Input. Watertown, USA. Pathfinder

Brookfield, S.D. (1986). Understanding and Facilitating Adult Learning. San Francisco: Jossey-Bass

Caffarella, R. S. (1993). Self-directed learning. In S.B. Merriam (ed), An Update on adult learning theory, no.57.San Francisco:Jossey-Bass.

Cooksey B and Kikula I (2005) When Bottom-up Meets Top-down: The Limits of Local Participation in Local Government Planning in Tanzania. Mkuki na Nyota Publisher. Dar es salaam. Coldevin, G. (2003). Participatory Communication: A Key to Rural Learning Systems. Rome: Food and Agriculture Organization of the United Nations.

Creswell, J. W. (2009). Research design: Qualitative, quantitative, and mixed methods approaches (3rd ed.). Los Angeles, CA: Sage Publications.

Ekoto C. E and P. Gaikwad (2015). The Impact of Andragogy on Learning Satisfaction of Graduate Students. American Journal of Educational Research American Journal of Educational Research Vol. 3, No. 11, 2015, pp 1378-1386.

Ferreira, D and G. MacLean (2017) Andragogy in the 21st century: Applying the Assumptions of Adult Learning Online. Language Research Bulletin, 32, ICU, Tokyo.

Greene K. and L. Larsen (2018) Virtual Andragogy: A New Paradigm for Serving Adult Online Learners. International Journal of Digital Society (IJDS), Volume 9, Issue 2, June 2018

Huesca, R. (2002). Tracing the History of Participatory Communication Approaches to Development: A Critical Appraisal. San Antonio, TX.

Nyerere, J. K. (1977). Ujamaa: Essays on Socialism; Oxford University Press; Dar es Salaam \& Nairobi.

Knowles, M. S. (1980). The modern practice of adult education: From pedagogy to andragogy. Englewood Cliffs, NJ: Cambridge Adult Education

Knowles, M. S. (1984). Andragogy in action. San Francisco: Jossey-Bass.

Knowles, M. S., Holton III, E. F., \& Swanson, R. A. (2014). The adult learner: The definitive classic in adult education and human resource development. New York, NY: Routledge.

In Economics and Development Papers. Issue No. 1:2003. Mzumbe University. Morogoro. Pp 84-114.

Loeng, S (2017) Alexander Kapp - the first known user of the andragogy concept. International Journal of Lifelong Education Vol.36 No. 6 Pp629-643,

Mlupilo, A. (2005). Opportunities and Obstacles to Development Programme (O \&OD). www.poralg.go.tz/programmes]. September 11, 2019

Mwakisisya H.J (2020) Meeting On-job Adult Learners' Special Needs: Insights from Improved Opportunities and Obstacles to Development System's Trainings in Tanzania. Journal of Education and Social Policy, Vol \&, No1, March 2020. Pp 8-17

Reischmann, J. (2017). Lifewide learning: Challenges for andragogy. Journal of Adult Learning, Knowledge and Innovation Vol 1, No.1 Pp 43-50.

Reischmann, J. (2015). Andragogy: Because "adult education" is not beneficial to the academic identity! In International perspectives in adult education - IPE 71 Pp 87-97)

URT (2008) The Study on Improvements of Opportunities and Obstacles to Development (O\&OD) Planning Process. Prime Minister's Office, Regional Administration and Local Government.

URT (2019) Guidelines for Improved Opportunities and Obstacles to Development (O and OD). President's Office, Regional Administration and Local Government.

Pretty J.N, et al (1995) Institutionalizing Adaptive Planning and Local Government Concerns: Looking to the Future in Nelson N and Wright S (Eds) - Power and Participatory Development, International Technology Publication.

Sharma. J and Yutaka Ohama (2007) Participatory Local Social Development- An Emerging Discipline. Bharat Book Centre. Lucknow. India

Tahir N (2014) The Impact of Training and Development on Employees Performance and Productivity: A case study of United Bank Limited Peshawar City, KPK, Pakistan. International Journal of Academic Research in Business and Social Sciences Vol. 4, No. 4 Pp 86-98 
Yogo T. (2001) An Overview of Regional Development Approach and Planning, Training Materials, JICA/NITC Training on Participatory Local Social Development. JICA. Nagoya, Japan

Yutaka, O (2002) Research Report- Basic Framework and Viewpoints of PLSD and Construction of its Evaluation framework. JICA and Institute of alternative Systems of Social Welfare and Development. Nihon Fukushi University, Japan.

Yutaka, O (2001) The Guidelines for PLSD, Planning Training Modules: Regional Planning for Poverty Alleviation in Sulawesi province, JICA, Indonesia. 